\title{
A METHOD FOR INTERACTIVE LEARNING
}

\author{
Satrio Pradono'; Maria Seraphina Astriani ${ }^{2}$; Jurike Moniaga ${ }^{3}$ \\ School of Computer Science, Bina Nusantara University \\ Jln. K.H. Syahdan No. 9, Jakarta 11480, Indonesia, \\ 1'satrio.pradono@gmail.com; ${ }^{2}$ seraphina.astriani@gmail.com; ${ }^{3}$ jurike@binus.edu
}

\begin{abstract}
Learning methods play an important role and receive special attentions in our life. We live in digital era, where everyone wants something efficient, effective, dynamic, fast and interactive. The term 'interactive' appears in two distinct strands of educational research discourse: one concerning pedagogy and the other concerning new technologies in education. Teaching students with traditional method where there is only one way of communication is no longer effective. The word interactive is the key to have an effective and efficient teaching and learning process where the teacher can grab students' attention and students can learn more in comparison to that of the traditional method.
\end{abstract}

Keywords: interactive; kinect; kinesthetic; multimedia; multitasking

\section{INTRODUCTION}

The young generation, born between the year of 1980 and 1994, has been characterized as the digitally native's generation because of their familiarity and reliance on the information and communication technology [1]. Thus, the education system for this generation may need to incorporate this aspect to provide a natural learning experience for the generation.

Comparing with the previous generations of students, the digitally-native students tend to be more active experimental learners, more proficient in multitasking, and strongly dependent on communication technologies for accessing information and for interacting with others. In order to reach the generation's potentials, the previous research has proved that an interactive learning tool such as utilizing Kinect is more favorable in order to create enjoyable and interesting interaction to boost student motivation [2].

The use of the interactive learning tools on the the digitally-native students can facilitate and enhance teaching and learning. Reference [3] conjectured that an interactive device such as Kinect can support kinesthetic pedagogical practices to benefit learners with strong bodily-kinesthetic intelligence. Kinect can help teacher to teach aspect requiring multimedia manipulation and can make the teaching and learning process becoming more interactive; thus, the student can gain more motivation to learn.

\section{Problem Statement}

Today, most of the education institutions are not supported with a decent Information and Communication Technology or ICT system that can support both the business aspect of the institution as well as the teaching and learning aspects [4]. They still use the old traditional method of teaching where the teaching and learning process is dominated with one-way communication mode. In this mode, the lecturer explains the teaching materials meanwhile the students take the notes and try to comprehend what the teacher has explained.

The above teaching and learning method is often ineffective and resulting on a condition where the teaching process becomes ineffective and discourages the student in learning [2]. These problems are initiated from the fact that the traditional method is less interactive between the both parties.

The current teaching and learning delivering method should be revised to align with the current young people adeptness of technology. Therefore, the problem lies ahead is that there is an urgent need to change the teaching and learning delivering method [1].

\section{METHOD}

Student interactivity is defined as the student's ability to response continually [5]. According to ref [2], interactivity has long been identified to contribute to successful teaching and learning. Because of that reason to solve the problem, we need interactivity in teaching and learning to create better environment to be more active and dynamic. Below is the method to create interactive learning environment.

\begin{tabular}{|c|c|c|c|c|}
\hline $\begin{array}{l}\text { What is } \\
\text { the } \\
\text { vision? }\end{array}$ & $\begin{array}{l}\text { Where } \\
\text { are we } \\
\text { now? }\end{array}$ & $\begin{array}{l}\text { Where are } \\
\text { we going } \\
\text { to be? }\end{array}$ & $\begin{array}{l}\text { How do } \\
\text { we get } \\
\text { there? }\end{array}$ & $\begin{array}{l}\text { How will you } \\
\text { know when you } \\
\text { get there? }\end{array}$ \\
\hline
\end{tabular}

Fig. 1: Method 
These steps are: (1) what is the vision? Define the vision to know what the goal is; (2) where are we now? Make a self-assessment to get a picture where is our current position for in terms of technology environment; (3) Where are we going to be? This step is to define whether there are any potential technologies that possible to be used in education to reach the vision. Reference [7] predicts that within the next few years the technology driving the Xbox Kinect will be a technological focal point in our classrooms. Though it has potential to facilitate natural interaction [2], Kinect needs to be situated in combination with software and other hardware in order to fabricate meaningful classroom interactions. Compared with IWBs (price ranges from about $\$ 800$ to $\$ 2,500$ ), Kinect is relatively cheap as it costs around $\$ 149$. If the classroom is equipped with a projector and a computer, Kinect can be regarded as an inexpensive add-on. (4) How do we get there? To create Interactive Presentation Slides, we need to analyze: (a) Requirement gathering, (b) List of features, (c) Implementation plan; (5) how will you know when you get where you want to be? To know where our current position is, we need to make a tool to monitor our steps and time frame.

\section{RESULTS AND DISCUSSION}

Motivated students are always easy to teach. Thus, motivating students are a great challenge facing by many teachers or educators. Traditional method of teaching is not effective and efficient as before because most of the students now are rather different in life style than the previous generation. Traditional method of teaching often makes the student unmotivated with boring classroom environment, disengages from the teaching material, and produces a passive classroom. On the other hand with the new method of teaching, interactive classroom has been proven otherwise.

Research indicates that kinesthetic activities and active lessons are essential for motivating students [10]. Active learning involving interactive classroom will lead to students who have strong interest to cooperate and to involve in discussion with others. In the new digital natives' era, students want to do more activities other than sitting in chair, holding a pen and books. The goal for doing this are the students are able to learn and remember better what they have learnt because of the involvement.

The reason why most students are better in sports, physical activities are because our students now are action-oriented and crave for kinesthetic activities [10]. The interactive teaching and learning environment has a close relation with technology and we all can find the technology almost everywhere, but why not every school has technology? The answer for this question is because everybody wants something quickly; do not have to be the best but fast. Investing technology in education is an investment where you may not see the profit until 10 years that is why people are not interested to invest technology in education. Implementing technology in school will make interactive teaching and learning environment easier to build and it will increase the visual-spatial skills, memory skills, multitasking ability to the students [11].

The current proposed implementation is as the following. (1) Target User: Teachers and students can use this system simultaneously. (2) Overall Analysis: Interactive presentation slide can be navigates using hand gesture waving or clapping to interact with the system. To use the system, teacher should stand $1 \mathrm{~m}$ away from Kinect and make sure there is not anything in between (see Fig. 2).

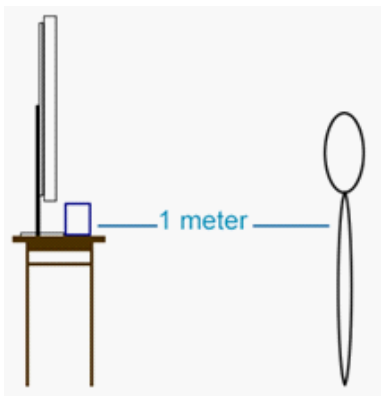

Fig. 2: Position

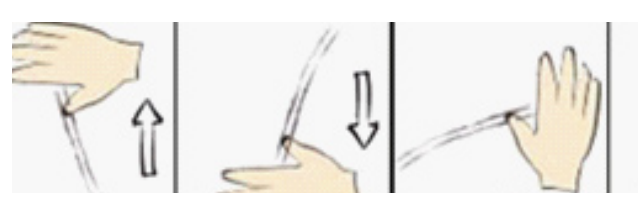

Fig. 3: Hand Gestures

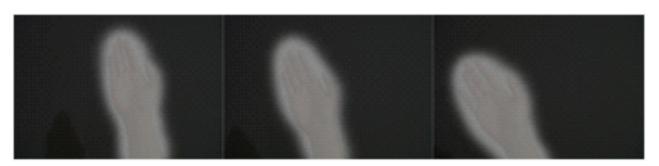

Fig. 4: Hand gesture detection-waving

(3) Features: to accommodate all the desired features in Interactive Presentation Slides, HTA [8] use top-down approach by checking the high-level goals and decompose task into sub goals and sub-sub goals.

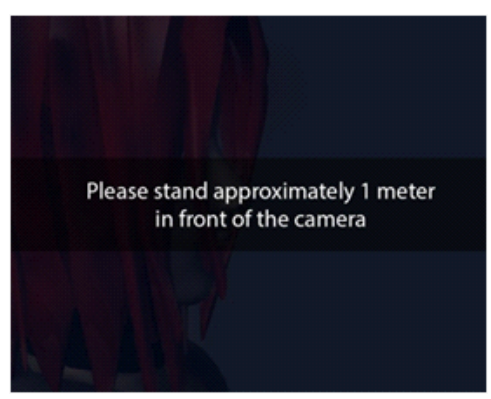

Fig 5: Lock Screen

\section{CONCLUSION}

The current generations who are digitally native and active require a new approach of teaching and learning because the traditional method has been proved to be not effective and efficient. To support the need, we have developed an interactive learning method to increase the current generation learning experiment. The new approach increases the visual spatial skills, memory skills, and multitasking ability. 


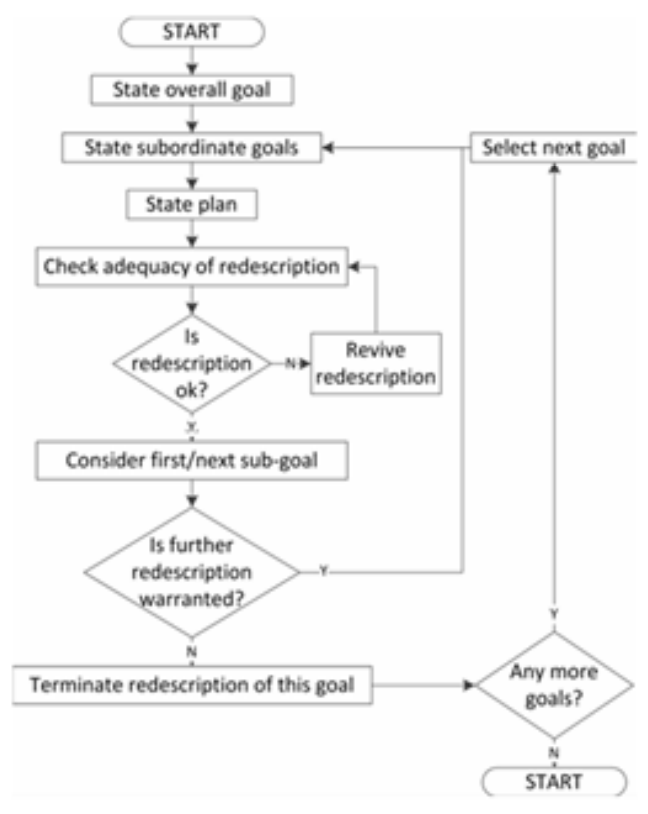

Fig. 6: The flowchart of HTA approach
[10] Laura, K., Swann, Motivating with Movements: Using Active Learning Practice to Increase Student Motivation and Engagement, url: https:// www.smcm.edu/educationstudies/pdf/rising-tide/ volume-4/Laura-Swann-MRP.pdf , 2012, Retrieved on Jan. 3, 2011

[11] Matthew, T., Recognizing Hand Gesture with Microsoft's Kinect, Palo Alto, Department of Electrical Engineering of Stanford University, 2011

\section{REFERENCES}

[1] Bennett, S.; Maton, K.; Kervin, L., The 'digital natives' debate: A critical review of the evidence, British Journal of Educational Technology 39 (5), pp. 775-786,2008

[2] Hsu, H. J., The Potential of Kinect as Interactive Educational Technology, 2nd International Conference on Education and Management Technology: IPEDR13, 2011

[3] Hsu, H. J., The Potential of Kinect in Education, International Journal of Information and Education Technology, 1 (5), pp. 365-370,2011

[4] Astriani, M., S., Pradono, S., IT Blueprint and School, Proceedings of the 10th WSEAS International Conference on Computational Intelligence, ManMachine Systems and Cybernetics, and Proceedings of the 10th WSEAS International Conference on Information Security and Privacy, Jakarta, Indonesia, pp. 160-167, 2011

[5] Beauchamp, G. and Kennewell, S., Interactivity in the classroom and its impact on learning. Computers and Education, 54, pp. 759-766, 2010

[6] Cassidy, A.,A Practical Guide to Information Systems Strategic Planning, 2nd Ed., Auerbach Publications, 2006

[7] Kissco, J., Kinect in education: The new technology focal point, url: http://www.k12mobilelearning. com/2011/01/kinect-the-new-technology-focalpoint-of-classrooms/, Retrieved on Jan. 3, 2011

[8] Diaper, D., Stanton, N., The Handbook of Task Analysis for Human-Computer Interaction, Lawrence Erlbaum Associates, Mahwah, New Jersey, 2004

[9] Stanton, N., A., Hierarchical task analysis: Developments, applications, and extensions, Applied Ergonomics, 37 (1), pp. 55-79, 2006 